\title{
Libertad, igualdad y propiedad en la sociedad capitalista
}

\author{
Freedom, Equality and Property in the Capitalist Society
}

CÉSAR RUIZ SANJUÁN*

\begin{abstract}
Resumen: En este artículo se aborda la crítica marxiana de las ideas de libertad e igualdad de la sociedad capitalista, así como la relación de las mismas con el concepto de propiedad que rige en esta forma de sociedad. Se muestra cómo dichas ideas se derivan de la esfera de la circulación del sistema capitalista, no encontrándose presentes como tales en la esfera de la producción. Se trata de poner de manifiesto que sólo con la escisión en clases que está a la base de la moderna sociedad burguesa y la subsiguiente expansión universal de las relaciones de intercambio puede surgir la apariencia de que las ideas de libertad e igualdad sean constitutivas del conjunto del sistema.

Palabras clave: Libertad, igualdad, propiedad, producción, circulación, capitalismo.
\end{abstract}

\begin{abstract}
This paper deals with the marxian critique of the ideas of freedom and equality of the capitalist society, as well as their relationship with the concept of property that prevails in this form of society. It shows up how these ideas are derived from the sphere of circulation of capitalist system, and are not to be found as such in the sphere of production. It is to point out that the appearance of the ideas of freedom and equality as constitutive of the whole system can arise only with the division of classes which is the basis of modern bourgeois society and the subsequent universal expanding exchange relations.
\end{abstract}

Keywords: Freedom, equality, property, production, circulation, capitalism.

\section{Introducción}

La crítica marxiana de las ideas de libertad e igualdad de la sociedad burguesa está dirigida poner de manifiesto la derivación de las mismas a partir de las relaciones de intercambio del sistema capitalista. Estas relaciones de intercambio son englobadas por Marx bajo la denominación de circulación simple. La esfera de la circulación simple constituye la superficie de la sociedad burguesa, es aquello que se presenta de manera inmediata a los individuos integrados en esta formación social. Pero esta esfera es sólo un momento de mediación del proceso global capitalista, y remite necesariamente a otros procesos que

Fecha de recepción: 15/09/2012. Fecha de aceptación: 27/09/2012.

* Universidad Complutense de Madrid. Facultad de Filosofía. Profesor Titular Interino. (ceruizsa@ filos.ucm.es) Líneas de investigación: Filosofía Política, Filosofía Social, Filosofía de la Historia. Publicaciones recientes: «La teoría marxiana del valor como crítica a las categorías de la economía política», en: Anales del Seminario de Historia de la Filosofía, no 30, 2013, pp. 137-155. «Desarrollo conceptual y evolución histórica. Consideraciones sobre los límites de la dialéctica», en: Ágora. Papeles de Filosofía, no 32, 2013, pp. 43-61. 
subyacen a la misma. Al mostrar cómo se articulan estos diversos procesos, se hace posible desplegar la crítica a las ideas burguesas de libertad e igualdad como representaciones que se desprenden de manera inmediata de las relaciones de intercambio.

Marx lleva a cabo de este modo una crítica fundamental de la teoría burguesa, la cual se limita a adoptar la perspectiva de la circulación y a considerar las relaciones que se presentan en esta esfera como las relaciones constitutivas de la sociedad burguesa. Frente a ello, la exposición marxiana muestra que la circulación no es más que una esfera abstracta del sistema capitalista, que tiene a su base las relaciones que se establecen en la esfera de la producción, en la cual desaparecen la libertad y la igualdad existentes en las relaciones de intercambio. Sólo con el surgimiento histórico de las relaciones sociales de producción capitalistas se ha desarrollado la circulación simple hasta el punto de abarcar la entera sociedad, por lo que las relaciones de intercambio, lejos de ser las relaciones constitutivas de la sociedad burguesa, tienen ellas mismas otros presupuestos que no resultan visibles desde la esfera de la circulación.

La exposición de Marx se dirige a descifrar las formas simples que constituyen las categorías de la teoría económica burguesa en términos de las relaciones sociales que se establecen en el proceso de producción, haciendo patente que dichas formas son sólo la expresión unilateral con la que aparece el proceso global capitalista en las relaciones de intercambio. Para ello es preciso mostrar que la circulación simple no es un proceso autosuficiente, puesto que no tiene en sí misma el principio de su autorrenovación. La crítica de Marx al modo de operar de la economía política con las categorías pone de manifiesto que la apariencia de inmediatez e independencia con que se presentan las formas económicas simples tiene como presupuesto el proceso de producción capitalista de mercancías. El hecho de que todos los productos del trabajo tengan ya un valor de cambio presupone la relación determinada entre el capital y el trabajo asalariado sobre la que se basa la sociedad capitalista, y sólo si se abstrae de esta relación de clase puede tomarse el valor de cambio como una forma económica que corresponde en esa determinación simple a todas las sociedades históricas. Lo que constituye el fundamento las formas simples no son las relaciones de intercambio, en las que los individuos se presentan como libres e iguales, sino la específica división en clases a partir de la que ha surgido la sociedad burguesa: esas formas no tienen una existencia independiente, sino que son sólo la expresión abstracta de las relaciones sociales históricamente más desarrolladas, y sólo pueden aparecer como simples y autónomas en la esfera de la circulación sobre el estado más desarrollado de su base histórica específica, de la cual precisamente hace abstracción la economía política.

A partir de aquí es posible impugnar la comprensión burguesa del trabajo como el título originario de propiedad. Esta comprensión se deriva de la forma en que se manifiesta la ley de apropiación en la circulación, donde la apropiación de trabajo ajeno aparece como resultado del propio trabajo ya objetivado en la mercancía. La exposición de Marx hace patente que la ley de apropiación capitalista, determinada por la relación entre el capital y el trabajo que se establece en el proceso de producción, es radicalmente distinta de la que se presenta a partir de la consideración de las relaciones equitativas del intercambio.

Puesto que los argumentos decisivos para la legitimación de las relaciones sociales burguesas tienen su origen en las representaciones que se surgen por sí mismas de la esfera de la circulación, es preciso mostrar que ésta es sólo la forma en que se manifiesta el proceso 
global en la superficie de la sociedad burguesa, y que sólo puede aparecer con ese carácter universal al estar erigida sobre proceso capitalista trabajo que tiene lugar en la esfera de la producción. Se trata de mostrar la necesaria integración de las dos esferas, pues sólo así es posible destruir la ilusión de que sean las formas económicas de la circulación y las ideas que se derivan de ellas lo originario y constitutivo de la sociedad burguesa. Marx pone de manifiesto que las ideas burguesas de libertad e igualdad y la explotación del trabajo asalariado son las dos caras de la misma moneda, pues sólo es posible que todos los miembros de la sociedad se presenten en la esfera de la circulación como personas libres e iguales una vez consumada la escisión en clases sobre la que se funda la sociedad capitalista.

\section{La integración de las esferas de la producción y la circulación en la sociedad capitalista}

Con la circulación simple (M-D-M) se refiere Marx a la circulación de mercancías y dinero en la sociedad capitalista, y el objeto de su exposición a este nivel es tematizar exclusivamente las determinaciones formales del valor de cambio en el proceso de intercambio de las mercancías, sin tomar en consideración aún explícitamente la esfera de la producción ${ }^{1}$. Lo primero que es preciso tener presente, por tanto, es que en la exposición marxiana la circulación simple no se refiere a una sociedad precapitalista, sino a una esfera del modo de producción capitalista: «No tenemos que ver aquí con el tránsito histórico de la circulación al capital. La circulación simple es más bien una esfera abstracta del proceso global de producción burgués $»^{2}$. En modos de producción anteriores ha habido circulación de mercancías y dinero, pero nunca han llegado a ser las relaciones dominantes. No es esta forma de circulación suprahistórica de la que parte Marx en su exposición, sino de la circulación que abarca la sociedad en su conjunto. Esta circulación sólo puede existir sobre la base de la producción capitalista de mercancías. No se trata, pues, de un tránsito histórico, como se ha interpretado frecuentemente, sino de un tránsito lógico en la exposición desde la esfera

1 La interpretación dominante dentro del marxismo sostiene, por el contrario, que con la circulación simple Marx estaría exponiendo el funcionamiento de una forma de sociedad precapitalista. El origen de esta interpretación se remonta a Engels, y ha sido sostenida por la mayor parte del marxismo ortodoxo. M. Rosental expresa esta comprensión con la mayor claridad: «Marx analiza primero la producción simple y circulación simple de mercancías, y muestra después que son un estadio preparatorio para el surgimiento del modo de producción capitalista. El dinero, explica Marx, es el último producto de la circulación mercantil y al mismo tiempo la primera forma de manifestación del capital. Sin el análisis de producción simple y circulación simple de mercancías no se puede entender tampoco la producción capitalista de mercancías. Aquélla crea los presupuestos para ésta. Su conexión es el tránsito de la una a la otra» (Die Dialektik in Marx' «Kapital», Berlin, Dietz, 1975, p. 45). Esta forma de interpretación se puede encontrar igualmente en la mayoría de las versiones divulgativas de la obra de Marx, como es el caso, por ejemplo, de E. Mandel, uno de los mayores representantes de esta interpretación, que sostiene que este nivel de la exposición de Marx refleja «una etapa transitoria entre una sociedad regida conscientemente por la cooperación del trabajo, y una sociedad en donde la disolución completa de los nexos comunitarios sólo deja lugar a leyes «objetivas», es decir, ciegas, «naturales», independientes de la voluntad de los hombres, para regir y gobernar las actividades económicas» (Tratado de economía marxista, México, Era, 1983, p. 65).

2 Urtext, MEGA II.2, p. 68. Las siglas corresponden a la edición: Karl Marx, Friedrich Engels: Gesamtausgabe (MEGA), hrsg. vom Institut für Marxismus-Leninismus beim Zk der KPdSU und vom Institut für MarxismusLeninismus beim Zk der SED; seit 1990: hrsg. von der Internationalen Marx-Engels-Stiftung (Amsterdam), Berlin, 1975 ff. La numeración corresponde respectivamente a la sección, el número romano, y al volumen, el número arábigo. 
de la circulación a la esfera de la producción que constituye su base. Ciertamente las dos esferas se requieren recíprocamente, pues el sistema capitalista sólo funciona a través de la conexión de ambas. Pero la producción constituye el fundamento de la circulación, porque sólo con el establecimiento del modo de producción capitalista la circulación de mercancías y dinero ha atravesado todas las relaciones sociales y las representaciones derivadas de ella se han establecido como socialmente válidas.

Así pues, esta circulación es «simple» no en el sentido de que pertenezca a una formación histórica aún no desarrollada en relación a la sociedad capitalista, sino en el sentido de que no está desarrollada categorialmente. Pero la circulación simple de mercancías, además de ser una forma no desarrollada conceptualmente, hace referencia al modo en que se presenta en la superficie de la sociedad capitalista el proceso global. Esto queda claramente explicitado en los Grundrisse, donde Marx se refiere a la circulación simple como lo que «aparece (erscheint) como lo inmediatamente existente en la superficie (das unmittelbar Vorhandne an der Oberfläche) de la sociedad burguesa $»^{3}$. La circulación de mercancías y dinero remite a un proceso subyacente, del que esta circulación constituye un momento abstracto, esto es, se presenta como una esfera separada, pero en realidad forma parte de dicho proceso. Marx afirma, por ello, que «la circulación no lleva en sí misma el principio de su autorrenovación $»^{4}$. Es preciso, por tanto, determinar conceptualmente la relación entre la circulación simple y el proceso del que se deriva, del cual es un momento de mediación a través del que se constituye el proceso global ${ }^{5}$.

Frente a la apariencia de simplicidad e independencia de la circulación simple, cuyas formas son consideradas por la economía política como correspondientes a todas las sociedades históricas, Marx pone de manifiesto que el intercambio generalizado de mercancías sólo tiene lugar en condiciones capitalistas desarrolladas. El análisis de la mercancía tiene que mostrar que «la forma de valor surge de la naturaleza del valor de la mercancía ... y no al revés, que el valor surge del valor de cambio» ${ }^{6}$. Esto significa que es preciso mostrar que la forma económica surge de las relaciones esenciales del modo de producción capitalista, esto es, de las relaciones en virtud de las cuales los productos del trabajo se refieren los unos a los otros como valores, y estas relaciones no son comunes a todos los modos de producción, sino que son unas relaciones sociales históricamente determinadas ${ }^{7}$. A diferen-

3 Grundrisse, MEW 42, p. 180. Las siglas corresponden a la edición: Karl Marx, Friedrich Engels: Werke (MEW), hrsg. vom Institut für Marxismus-Leninismus beim Zk der SED, Berlin, 1956 ff., y el número corresponde al volumen.

4 Ibid., 179. En una carta a Engels de esta época insiste Marx sobre la importancia fundamental de esta cuestión: «La circulación simple no tiene en sí misma el principio de su autorreproducción y remite, por tanto, más allá de ella» (Carta del 2/4/1858, MEW 29, p. 317).

5 En este sentido indica M. Heinrich que la coherencia teórica de la exposición de Marx exige mostrar «que la circulación simple hace necesaria una determinación formal adicional, que existe un tránsito conceptual de la circulación simple al capital» (Die Wissenschaft vom Wert. Die Marxsche Kritik der politischen Ökonomie zwischen wissenschaftlicher Revolution und klassischer Tradition, Münster, Westfälisches Dampfboot, 2001, p. 255).

6 Das Kapital, MEW 23, p. 75.

7 Sobre esta cuestión señala H. Brentel que «ser valor no es una «propiedad» suprahistórica de los productosmercancías en general, desde el intercambio comercial no desarrollado hasta el producto industrial, sino que en sentido estricto hay que comprenderlo sólo como valor-capital» (Soziale Form und Ökonomisches Objekt. Studien zum Gegenstands- und Methodenverständnis der Kritik der politischen Ökonomie, Opladen, Westdeutscher Verlag, 1989, p. 266). 
cia de la economía burguesa, Marx no considera el intercambio de mercancías y el proceso de generación de valor como algo suprahistórico, sino como el modo específico en que se constituye la moderna sociedad burguesa.

«En el desarrollo se muestra, por tanto, no sólo el carácter histórico de las formas que, como el capital, pertenecen a determinada época histórica; sino que determinaciones como el valor, que aparecen como puramente abstractas, indican la base histórica de la que son abstraídas, pues únicamente sobre ella pueden aparecer en esa abstracción ... El concepto económico de valor no se encuentra entre los antiguos. El concepto de valor pertenece por completo a la economía más reciente, puesto que constituye la expresión más abstracta del capital mismo y de la producción basada en él. En el concepto de valor se revela su secreto» ${ }^{8}$

La teoría marxiana del valor va dirigida contra una comprensión ahistórica de la mercancía. Consiste precisamente en la crítica de aquellas concepciones que consideran que al producto le corresponde un valor de cambio como si fuese un atributo natural. Con ello se está presuponiendo justamente lo que hay que mostrar a través del desarrollo de las categorías, lo específicamente social. Marx quiere problematizar lo que la economía política toma como un hecho natural, y como tal correspondiente a todas las formaciones sociales ${ }^{9}$.

El desarrollo de las formas desde las más simples hasta las formas acabadas hace patentes las condiciones de las que surgen las abstracciones objetivadoras con las que opera la economía política, mostrando el contenido de las formas económicas en las relaciones sociales de producción del sistema capitalista. La crítica marxiana está dirigida a mostrar que el análisis de las «determinaciones abstractas apunta siempre a la base histórica determinada más concreta» ${ }^{10}$ que subyace a esas abstracciones. Esto significa que el intercambio mercantil que está al comienzo de la exposición teórica de Marx no es el intercambio de mercancías que se ha dado en las distintas sociedades históricas, sino el intercambio mercantil generalizado que abarca todas las relaciones sociales, que en la historia se ha presentado sólo en la moderna sociedad burguesa.

«La forma de mercancía es la forma más general y menos desarrollada de la producción burguesa, por eso se presenta ya tempranamente, aunque no en el mismo modo dominante, por tanto, característico, que tiene hoy en día» ${ }^{11}$

Por lo tanto, frente a la economía política, que cree posible explicar la sociedad burguesa con formas simples y ahistóricas, lo que le permite ver a esta formación social in nисе en todas las sociedades anteriores, Marx muestra que esas formas sólo se presentan

8 Grundrisse, MEW 42, p. 667.

9 Ilenkov observa a este respecto que a la economía política «la forma de producción capitalista le parecía la forma «natural» eterna de toda producción. De ello deriva el carácter ahistórico de su abstracción ... Si la deducción de las categorías va unida a una concepción ahistórica del objeto que por medio de ellas es reproducido conceptualmente, adquiere inevitablemente un carácter puramente formal» (La dialettica dell'astratto $e$ del concreto nel Capitale di Marx, Milano, Feltrinelli, 1961, pp. 149-150).

10 Zur Kritik der politischen Ökonomie, MEW 13, p. 116.

11 Das Kapital, MEW 23, p. 97. 
en esa simplicidad en las relaciones sociales más desarrolladas históricamente, de las cuales constituyen sólo una expresión abstracta. En la medida en que no se comprendan como momentos de esa formación social, de la sociedad capitalista, ocultarán las verdaderas relaciones sociales de producción que constituyen la base de esas categorías y las hace presentarse con esa apariencia de simplicidad y autonomía. De este modo «no se ve que en la determinación más simple del valor de cambio y del dinero ya está contenida de manera latente la contraposición de trabajo asalariado y capital» ${ }^{12}$. Al no ver que lo que está a la base de la constitución del valor de cambio en la sociedad burguesa es esta relación de producción específica, se toma como una forma económica correspondiente en esta determinación simple a todos los modos de producción históricos. Y como señala Marx en una frase teóricamente central en este contexto, al tomar esta forma de valor «como forma natural eterna de producción social, se pasa también por alto necesariamente lo específico de la forma de valor, por tanto, de la forma de mercancía y, más desarrollada, de la forma de dinero, y la forma de capital» ${ }^{13}$.

Las formas simples de la esfera de la circulación, pues, no son consideradas por Marx como formas correspondientes a todas las sociedades históricas, sino como las formas más abstractas del modo de producción capitalista, como momentos, por tanto, de la formación social históricamente más desarrollada, dentro de cuyas relaciones sociales complejas aparecen como totalmente simples. No se trata en ningún caso de que Marx parta de categorías suprahistóricas que luego va especificando históricamente en el curso de la exposición, tal y como se ha interpretado a menudo, sino que parte desde el principio de categorías específicas del modo de producción capitalista, y va progresando desde sus determinaciones más abstractas hasta las más concretas, en las cuales se hace efectivamente visible su constitución histórica ${ }^{14}$.

Lo que resulta importante retener para comprender la sistemática de la exposición de Marx es que la apariencia de la esfera del intercambio en la que permanece apresada la conciencia burguesa, y que suministra asimismo la base a las categorías de la economía política, surge por sí misma de las relaciones sociales que establecen los hombres entre sus trabajos (no directamente, sino a través de los productos de sus trabajos) dentro del modo de producción capitalista. Sólo en un sistema de trabajo asalariado en el que se produce privadamente y el trabajo vale como social a posteriori a través del intercambio de los productos en el mercado, adoptan los productos del trabajo la forma de mercancía, y entonces se convierte la circulación de mercancías y dinero en la esfera que abarca la entera sociedad. A partir de este momento se presentan las relaciones que establecen los individuos en esta esfera regidas por el intercambio de equivalentes, y con ello la apariencia de que la apropiación está basada en el trabajo propio.

12 Grundrisse, MEW 42, p. 173.

13 Das Kapital, MEW 23, p. 95.

14 En relación a ello indica G. Stapelfeldt: «En el curso lógico de la exposición, comenzando con la mercancía como el nivel más abstracto, hay que mostrar al mismo tiempo la génesis de las determinaciones formales históricas - no su proceso histórico de surgimiento - y con ello la generalización de la forma de mercancía: éste es, dirigido críticamente contra la teoría burguesa, el programa marxiano de crítica de la economía política» (Das Problem des Anfangs in der Kritik der politischen Ökonomie. Zum Verhältnis vom Arbeitsbegriff und Dialektik, Frankfurt a. M., Campus Verlag, 1979, p. 76). 
Esta representación espontánea que se reproduce por sí misma en la conciencia de los agentes que forman parte de ese sistema social constituye asimismo la base de los conceptos fundamentales de la teoría burguesa. Éstos tienen, por tanto, un fundamento objetivo en las relaciones sociales que se establecen en la superficie de la sociedad burguesa y en las ideas a ellas correspondientes, lo que lleva a Marx a hablar de «formas objetivas de pensamiento» ${ }^{15}$ que son válidas para esa formación social. Son «resultados acabados» ${ }^{16}$, pues son formas ya configuradas a partir de las relaciones que establecen los individuos en esa sociedad, constituyendo el resultado de las determinaciones formales objetivas dadas de manera inmediata. Las categorías de la economía burguesa son, por tanto, el producto teórico de unas relaciones sociales específicas, con las cuales se encuentran los individuos que forman parte de esa sociedad como algo dado inmediatamente. Por ello la crítica inmanente que Marx desarrolla de las categorías de la economía política conlleva asimismo la crítica de la conciencia espontánea de la sociedad burguesa y de las relaciones a partir de las que surge esa conciencia como reflejo directo de esas relaciones.

De este modo, la exposición marxiana lleva a cabo la disolución de la apariencia de inmediatez, independencia y simplicidad que tienen las formas económicas que se presentan en la circulación, mostrando que están mediadas por las relaciones que se establecen en el proceso de producción, que son momentos abstractos de dicho proceso, del cual dependen enteramente, y que su aparente simplicidad se debe precisamente a que en ellas se hace abstracción de este proceso que está a su base. El progreso de la exposición consuma la destrucción de la pretendida autonomía y autofundamentación de esas formas económicas, haciendo visible los verdaderos procesos a partir de los que éstas se constituyen. Se avanza así desde los conceptos abstractos del comienzo, la mercancía y el dinero en la circulación simple, hasta el capital, en el que el valor alcanza su verdadera autonomía en un movimiento que consiste en su puro incremento, movimiento que sólo puede realizarse a partir de la relación determinada que se establece en la esfera de la producción entre el trabajo y el capital.

La pregunta por la constitución de la forma económica va a parar así a la relación de clase constitutiva de la sociedad capitalista, en la que rige de hecho un principio de apropiación distinto al que se presenta en las relaciones del intercambio mercantil. A partir de las determinaciones económicas formales de la circulación simple, el proceso de intercambio aparece como un intercambio de equivalentes. La propiedad de la mercancía antecede al intercambio, y esta propiedad «se presenta como proviniendo inmediatamente del trabajo de su poseedor y el trabajo como el modo original de apropiación» ${ }^{17}$. A partir de estas premisas, sólo es posible apropiarse de la mercancía ajena a través del intercambio de la propia mercancía en la que esté contenida una cantidad de trabajo equivalente al de la mercancía que se intercambia. El trabajo propio parece ser el único medio para apropiarse de trabajo ajeno. Surge la apariencia, pues, de que el trabajo propio sea el origen de toda propiedad:

15 Das Kapital, MEW 23, p. 90.

16 Ibid., p. 89.

17 Urtext, MEGA II.2, p. 47. 
«En tanto que la mercancía como valor de cambio es sólo trabajo objetivado, y desde el punto de vista de la circulación, la cual es sólo el movimiento del valor de cambio, sólo es posible apropiarse de trabajo ajeno objetivado por medio del intercambio de un equivalente, la mercancía no puede ser, de hecho, nada más que la objetivación del propio trabajo, y como este último es el proceso de apropiación fáctica de productos naturales, aparece asimismo como el título jurídico de propiedad» ${ }^{18}$

Uno de los objetivos fundamentales de la exposición teórica de Marx será poner de manifiesto la verdadera ley de apropiación en la que se basan las relaciones económicas burguesas. Frente a la ley de apropiación basada en el trabajo propio, en la que según la economía política se fundan las relaciones económicas burguesas, Marx hará patente que la ley de apropiación que está a la base del sistema capitalista es muy distinta a ésta, pues está determinada por la relación de intercambio entre el capital y el trabajo que se establece en el proceso de producción, y no por las relaciones de intercambio que se presentan en la circulación, las cuales sólo hacen de mediación en el proceso global19.

Esta dimensión de la crítica marxiana no está dirigida sólo contra la economía burguesa, sino también contra aquellos teóricos socialistas que ven el proceso de la circulación como algo independiente de las relaciones de producción capitalistas, y consideran el intercambio mercantil como la realización de la libertad y la igualdad humanas. Proudhon es el teórico socialista por antonomasia de esta apariencia de autosuficiencia de la esfera de la circulación. Concibe a partir de la circulación simple un sistema de intercambio mercantil simple, esto es, un sistema de intercambio en el que la mercancía representa el valor objetivo del trabajo, y estas mercancías se intercambiarían entre sí directamente, sin mediación del dinero. De este modo, trata de utilizar las ideas que se derivan de la circulación contra la propia sociedad capitalista. Marx denomina al socialismo de Proudhon como la «utopía del filisteo», y considera que es el resultado de la mentalidad pequeñoburguesa que ve en la producción y el intercambio mercantil «el nec plus ultra de la libertad humana y la independencia individual» ${ }^{20}$. Al igual que la economía política, Proudhon no es capaz de ver el contenido social específico de las formas económicas. Marx critica sus ideas como el resultado de una comprensión radicalmente errónea $^{21}$, pero pone de relieve que dichas ideas tienen a su base una determinada objetividad, son el reflejo teórico de las representaciones que se desprenden de la circulación.

18 Ibid., p. 49.

19 Lo esencial es comprender que en tanto que es un momento de mediación, la esfera de la circulación es sólo la forma de manifestación de un proceso subyacente: «La circulación considerada en sí misma es la mediación de extremos presupuestos. Pero ella no pone estos extremos. Por consiguiente, como todo de la mediación, como proceso total mismo, ella tiene que ser mediada. Su ser inmediato es, por tanto, pura apariencia (Ihr unmittelbares Sein ist daher reiner Schein). Es el fenómeno de un proceso que sucede a sus espaldas» (ibid., p. 64).

20 Das Kapital, MEW 23, p. 84.

21 Marx critica a Proudhon que permanezca apresado en la apariencia de la autonomía del dinero como forma general de equivalente: «Uno se podría imaginar que se puede imprimir a todas las mercancías simultáneamente el sello de la intercambiabilidad inmediata, como uno se podría imaginar que se puede hacer Papa a todos los católicos» (ibid., p. 82). Lo que no entiende una teoría socialista como la Proudhon, que pretende abolir el dinero y conservar el intercambio de mercancías, es que las propiedades del dinero, que es el equivalente general, se deben sólo a la relación en que se encuentra con las otras mercancías, que sólo es tal porque todas las mercancías se refieren a él como equivalente general, y esto tiene que ser necesariamente así para que las mercancías puedan referirse unas a otras como valores. 


\section{Libertad e igualdad como ideas correspondientes a la esfera de la circulación del sis- tema capitalista}

En la esfera de la circulación, los hombres se relacionan entre sí meramente como intercambiadores de productos, lo que hace que se presenten unos a otros como individuos libres e iguales. Marx pone de manifiesto que este proceso de intercambio es la «base real» de las ideas de libertad e igualdad de la sociedad moderna:

«El proceso del valor de cambio desarrollado en la circulación no sólo respeta, pues, la libertad y la igualdad, sino que éstas son su producto; dicho proceso es la base real (reale Basis) de las mismas. Como ideas puras son expresiones idealizadas de sus diversos momentos (Als reine Ideen sind sie idealisierte Ausdrücke seiner verschieden Momente); al desarrollarse en relaciones jurídicas, políticas y sociales, simplemente son reproducidas y elevadas a otras potencias» ${ }^{22}$

Pero esta esfera de la circulación no es algo autónomo, sino que se levanta sobre la estructura específica del proceso de trabajo capitalista, que supone la división de la sociedad en trabajadores asalariados y propietarios de los medios de producción. Esta dualidad es pasada por alto sistemáticamente por la economía política, que se limita a tomar las categorías tal y como se dan de manera inmediata en la experiencia, como aparecen en la esfera de la circulación. Dado que en esta esfera domina la ley del intercambio de equivalentes, la economía política proyecta esta ley sobre el conjunto del sistema, construyendo sus teorías a la medida de las ideas que resultan de la circulación simple. Esto implica comprender el trabajo como la causa original de la propiedad, pues si ha de respetarse el intercambio de equivalentes, sólo puede adquirirse la mercancía ajena a través del trabajo propio: «Supuesta la ley de la apropiación por el trabajo propio, y éste es un supuesto que surge de la consideración de la circulación misma, no es un supuesto arbitrario, se presenta por sí mismo en la circulación un reino de libertad e igualdad burguesas fundado en esta ley» ${ }^{23}$.

De este modo, la economía política, al adoptar la perspectiva de la circulación, pierde de vista que los individuos sólo pueden encontrarse como sujetos libres e iguales en el proceso de intercambio si primero se ha producido la división de la sociedad en clases, de modo que una parte de la sociedad haya quedado desposeída de los medios de producción y esté obligada a vender su fuerza de trabajo, y otra parte de la sociedad detente la propiedad de dichos medios, que en relación con el trabajo asalariado se han convertido en capital, estableciéndose así la estructura constitutiva del sistema capitalista: lo que Marx denomina «relación de capital (Kapitalverhältnis)» ${ }^{24}$. En la esfera de la circulación no resulta visible esta relación estructural que está a la base del modo de producción capitalista, pues, de hecho, en lo que consiste la esfera de la circulación es precisamente en borrar de manera sistemática la diferencia específica entre los individuos. Considerados como sujetos que intercambian, los individuos aparecen en una relación de total igualdad entre sí, no es posible establecer ninguna diferencia entre ellos. También la idea

22 Urtext, MEGA II.2, p. 60.

23 Ibid., pp. 49-50.

24 Das Kapital, MEW 23, pp. 350 y ss. 
de libertad burguesa es resultado de las relaciones que tienen lugar en la esfera de la circulación, pues para que pueda realizarse el intercambio los individuos tienen que ser jurídicamente libres:

«En tanto que esta diversidad natural de los individuos y de sus mercancías ... constituye el motivo de la integración de estos individuos, de su relación social como sujetos que intercambian, relación en la que están presupuestos como iguales y se confirman como tales, a la determinación de igualdad se agrega la de libertad. Aunque el individuo A siente la necesidad de la mercancía del individuo B, no se apropia de ella por la fuerza, ni viceversa, sino que se reconocen mutuamente como propietarios, como personas cuya voluntad impregna sus mercancías. En este momento aparece la noción jurídica de persona y, en la medida en que está contenida en ella, la de libertad» ${ }^{25}$

De este modo aparecen las ideas de libertad e igualdad de la sociedad burguesa como resultado de las relaciones que los individuos establecen entre sí el proceso de intercambio, y en la medida en que no se ve que este proceso es a su vez resultado del sistema de trabajo privado del modo de producción capitalista, se pueden hacer extensivas estas ideas al conjunto de la sociedad, considerándolas como las ideas constitutivas de la sociedad burguesa. Pero, en realidad, como Marx pone de manifiesto frente a las teorías burguesas, la esfera de la circulación es el ámbito que produce efectivamente las ideas de libertad e igualdad: «No sólo se trata, pues, de que la libertad y la igualdad sean respetadas en el intercambio basado en valores de cambio, sino que el intercambio de valores de cambio es la base productiva, real, de toda igualdad y libertad (die produktive, reale Basis aller Gleichheit und Freiheit)» ${ }^{26}$.

El hecho de que Marx haga patente en el curso de su exposición que esta libertad y esta igualdad son mera apariencia en la relación del trabajador con el capitalista, no significa en absoluto que no sean reales. La forma de sociedad basada en la intercambio de mercancías es la que ha introducido en la historia al individuo libre y la igualdad formal. Al tener que tomar en consideración la voluntad de otro aparece el principio del cambio como algo objetivo, algo independiente de cada individuo.

Marx caracteriza en El Capital «la esfera de la circulación o del intercambio de mercancías» como «un verdadero Edén de los derechos humanos innatos»:

«Lo único que impera aquí es la libertad, la igualdad, la propiedad y Bentham. ¡Libertad! Pues el comprador y el vendedor de una mercancía, por ejemplo, de la fuerza de trabajo, sólo están determinados por su libre voluntad. Firman un contrato como personas libres y jurídicamente iguales. El contrato es el resultado final en el que sus voluntades se dan una expresión jurídica común. ¡Igualdad! Pues sólo se relacionan entre sí como poseedores de mercancías e intercambian equivalente por equivalente. ¡Propiedad! Pues cada uno sólo tiene disposición sobre lo suyo. ¡Bentham! Pues cada uno de ellos sólo se ocupa de sí mismo. El único poder que los une y los relaciona es el de su egoísmo, su ventaja particular, sus intereses privados $»^{27}$

25 Grundrisse, MEW 42, p. 169.

26 Ibid., p. 170.

27 Das Kapital, MEW 23, pp. 189-190.

Daímon. Revista Internacional de Filosofía, no 61, 2014 
La exposición marxiana está dirigida a mostrar que en las relaciones establecidas en el proceso de trabajo se desvanecen esta libertad y esta igualdad que dominan en la esfera de la circulación, desarrollando de este modo una crítica fundamental de las formas de conciencia burguesas ${ }^{28}$. Puesto que la economía política no desarrolla de manera consecuente la relación entre la esfera de la circulación y la de la producción, no puede comprender que los individuos sólo pueden relacionarse como sujetos libres e iguales en el proceso de intercambio una vez que se ha establecido históricamente el capital industrial, esto es, una vez que la mayor parte de la población ha sido desposeída de sus medios de producción y tiene que convertirse en fuerza de trabajo asalariada.

De este modo, la esfera de la circulación, que constituye la base de la «trinidad de propiedad, libertad e igualdad» ${ }^{29}$, se presenta en el desarrollo de la exposición como mera forma de manifestación del proceso de trabajo capitalista, que en la medida en que es considerada como una esfera autónoma tanto por la conciencia espontánea como por la economía política, no es más que una forma invertida bajo la que se presenta el proceso global capitalista ${ }^{30}$. Los miembros de la sociedad sólo pueden encontrarse en la esfera de la circulación como poseedores de equivalentes y como individuos libres e iguales en la medida en que ya pertenecen a una determinada clase (históricamente constituida), pero esta diferencia queda más allá de la circulación. Esta dualidad constituye el núcleo a partir del que se despliega de la crítica marxiana.

«El modo en que se han convertido en propietarios de estas mercancías es un proceso que sucede a espaldas de la circulación simple y que está ya consumado antes de que ésta comience. La propiedad privada es un presupuesto de la circulación, pero el proceso de apropiación mismo no se muestra, no aparece dentro de la circulación, está más bien presupuesto a ella ... Cómo se han convertido en propietarios privados, esto es, cómo se han apropiado de trabajo objetivado, es una circunstancia que no parece caer en absoluto dentro de la consideración de la circulación simple» ${ }^{31}$

Las teorías de la economía política, incluyendo las de Adam Smith y David Ricardo, que fueron los que más lejos llegaron en este sentido, no consiguieron comprender con claridad esta piedra angular del sistema global que constituye el punto de integración de las esferas de la

28 A este respecto señala Kosík: «El fenómeno más elemental y más banal de la vida económica de la sociedad capitalista - el simple intercambio de mercancías -, en el que los hombres intervienen como simples compradores o vendedores, en un ulterior examen, resulta ser una apariencia superficial, que se haya determinada y mediatizada por procesos profundos y esenciales de la sociedad capitalista, esto es, por la existencia y explotación del trabajo asalariado. La libertad y la igualdad del simple intercambio, en el sistema capitalista de producción de mercancías se desarrolla y se realiza como desigualdad y falta de libertad» (Dialéctica de lo concreto, México, Grijalbo, 1967, p. 77).

29 Urtext, MEGA II.2, p. 60.

30 Esta inversión se mostrará como tal en el curso de la exposición categorial, a través del progresivo desarrollo las formas simples del comienzo: «La propiedad del trabajo ajeno es mediada por el equivalente del propio trabajo. Esta forma de propiedad - del mismo modo que la libertad y la igualdad - está puesta en esta relación simple. En el desarrollo ulterior del valor de cambio esto se transformará (in der weitren Entwicklung des Tauschwerts wird sich dies verwandeln) y se mostrará finalmente que la propiedad privada del producto del propio trabajo se identifica con la separación de trabajo y propiedad; de tal forma que el trabajo será igual a crear propiedad ajena, y la propiedad a dominar trabajo ajeno» (Grundrisse, MEW 42, pp. 163-164).

31 Urtext, MEGA II.2, p. 48. 
producción y la circulación. Su insuficiencia está determinada por el hecho de tomar las categorías tal y como se dan de manera inmediata, tal y como aparecen en la circulación. Pero como señala Marx, «el proceso por el que surgen las mercancías y, por tanto, también el proceso de su apropiación originaria, se encuentran más allá de la circulación» ${ }^{32}$. Esto significa que no es posible deducir el proceso apropiación de las mercancías a partir de la esfera de la circulación. Y, sin embargo, esto es precisamente lo que hace la economía política. Al no haber comprendido correctamente el modo en que se articulan las dos esferas, lo que hacen los economistas burgueses para solucionar las contradicciones que se presentan en sus teorías es construir un proceso más allá de la esfera del intercambio que responde a las ideas que resultan de ésta.

El único modo de superar esta ilusión es comprender que la esfera de la circulación no es más que la forma de manifestación en la superficie de la sociedad burguesa del proceso subyacente de la producción capitalista. Sólo entendiendo el modo en que se integran ambas esferas es posible descifrar la apariencia invertida en que se presentan las relaciones sociales burguesas a la percepción inmediata de las mismas. Pues los miembros de la sociedad se presentan en la esfera del intercambio como individuos que tienen la misma relación los unos con los otros, de modo que dicha esfera consiste precisamente en eliminar toda diferencia que se pueda presentar entre los individuos: «Como sujetos del intercambio, su relación es la de igualdad. Es imposible encontrar algún tipo de diferencia o incluso de contraposición entre ellos, ni siquiera una disparidad $\gg^{33}$. Esta igualdad social es resultado de una desigualdad previamente existente, pero si se considera sólo la esfera de la circulación, lo único que aparecen aquí son sujetos iguales que llevan a cabo actos de intercambio, no siendo posible establecer desde aquí ninguna distinción entre los $\operatorname{mismos}^{34}$. La idea de libertad burguesa surge también del proceso de intercambio. Pero mientras que en el intercambio la igualdad la pone la forma, el valor de cambio, la libertad la pone el contenido, el valor de uso. El significado que tiene el valor de uso a este nivel de la exposición es sólo el de ser un no valor de uso para el poseedor, y representa el motivo impulsor del intercambio: «De la misma manera que la forma económica, el intercambio, pone la igualdad de los sujetos en todos los sentidos, el contenido, la materia ... pone la libertad» ${ }^{35}$.

Lo que resulta fundamental retener es que Marx nos ha dejado señalado el lugar sistemático en el que tiene que llevarse a cabo la descodificación de la visión que la sociedad burguesa tiene de sí misma, el cual se encuentra en la inserción de la esfera de la circulación en el proceso más profundo que yace tras dicha esfera, el proceso de producción del capital, del cual ésta es el resultado visible. Puesto que la economía política no se hace cargo de que sólo una vez establecido el modo de producción capitalista pueden relacionarse los individuos como sujetos libres e iguales en sus relaciones de intercambio, tiene que incurrir necesariamente en una comprensión errónea del proceso global.

Marx pone de manifiesto que esto tiene como consecuencia la transformación que opera la economía burguesa de las determinaciones formales sociales en propiedades naturales, consi-

32 Ibid., p. 47.

33 Grundrisse, MEW 42, p. 167.

34 Como expresa Marx muy gráficamente: «Un trabajador que compra una mercancía por 3 sh. aparece ante el vendedor en la misma función, en la misma igualdad - en la forma de $3 \mathrm{sh}$. - que el rey que hace lo mismo. Se extingue toda diferencia entre ellos» (ibid., p. 172).

35 Ibid., p. 170. 
derando por ello como natural, y como tal correspondiente a todas las sociedades históricas, algo que es puramente social, propio de una forma de sociedad históricamente determinada. Se considera, por tanto, que el capital es una propiedad de las cosas, y que el hombre es por naturaleza un trabajador libre ${ }^{36}$. Al mismo tiempo, las ideas que surgen de la esfera del intercambio son elevadas al rango de verdad absoluta de la sociedad en su conjunto, y entran así en una contradicción frontal con la realidad de una sociedad dividida en clases, una de las cuales no tiene más remedio que trabajar para la otra, que se enriquece cada vez más a expensas de la clase que trabaja para ella. Para solucionar estas contradicciones, lo que hace la teoría burguesa es retrotraer la estricta validez de la ley de apropiación a una época primigenia, en la que todavía no había propiedad, como único modo de justificar el desfase sangrante que existe entre la realidad social del capitalismo y las ideas burguesas de libertad e igualdad. Estas ideas propias de la economía política son asumidas de manera acrítica por muchos teóricos socialistas. Esto provoca el siguiente comentario de Marx, que merece ser citado en toda su extensión:

«Por otra parte, se puede observar también la tontería de aquellos socialistas (especialmente los franceses, que quieren demostrar que el socialismo es la realización de las ideas de la sociedad burguesa proclamadas por la Revolución Francesa) que afirman que el intercambio, el valor de cambio, etc., originariamente (en el tiempo) o según su concepto (en su forma adecuada) son un sistema de libertad e igualdad para todos, pero que han sido falseados por el dinero, el capital, etc. O también que la historia ha hecho hasta ahora intentos aún fracasados de realizar esas ideas en el modo correspondiente a su verdad, por lo que ha de ser proporcionada la historia auténtica de esas relaciones en lugar de la falsa. Hay que responderles lo siguiente: el valor de cambio, o más precisamente, el sistema monetario es, de hecho, el sistema de la igualdad y la libertad, y lo que se les opone perturbándolas en el desarrollo del sistema son perturbaciones inmanentes a éste, precisamente la realización de la igualdad y la libertad, que se acreditan como desigualdad y falta de libertad. El deseo de que el valor de cambio no se desarrolle en capital, o que el trabajo que produce valor de cambio no se desarrolle en trabajo asalariado, es un deseo tan piadoso como estúpido. Lo que distingue a estos señores de los apologistas burgueses es, por una parte, la percepción de las contradicciones que encierra el sistema; por otra parte, el utopismo, el no comprender la diferencia necesaria entre la conformación real y la ideal (notwendigen Unterschied zwischen der realen und idealen Gestalt) de la sociedad burguesa y, por tanto, querer llevar a cabo la empresa superflua de realizar nuevamente la expresión ideal misma de esa sociedad, que sólo es, de hecho, la imagen refleja de esa realidad» ${ }^{37}$

36 M. Postone se ha referido a esta concepción del trabajo como una concepción «transhitórica», en la que el trabajo se comprende «en términos de una actividad social dirigida a fines que media entre los hombres y la naturaleza, creando productos específicos para satisfacer determinadas necesidades humanas. El trabajo, así entendido, se considera como perteneciente al corazón mismo de toda vida social: constituye el mundo social y es fuente de la riqueza social. Esta concepción atribuye al trabajo social transhistóricamente lo que Marx analiza como una característica históricamente específica del trabajo en el capitalismo» (Time, labor and social domination. A reinterpretation of Marx's critical theory, Cambridge, Cambridge University Press, 1993, p. 18).

37 Grundrisse, MEW 42, p. 174. 
En efecto, desde estas posiciones «socialistas» se pretende oponer la imagen ideal que arroja de sí misma la sociedad burguesa a esa propia sociedad, afirmando que ésta no es capaz de realizar esas ideas, por lo que se requiere de una organización social distinta en la que esas ideas puedan ser efectivamente realizadas. Frente a ello, Marx pone de manifiesto que dicha realidad social no es una consumación fallida de esas ideas, ni tampoco una degeneración de las mismas, sino precisamente el sistema realizado de la libertad y la igualdad, pues éstas son las representaciones que se desprenden necesariamente de la circulación como esfera que abarca toda la sociedad, lo cual sólo puede tener lugar sobre la base del modo de producción capitalista. Al elevar las ideas que surgen de la circulación simple a las bases de una teoría, se tiene la pretensión estéril de querer realizar lo que ya está realizado y por medio de esta realidad se ha configurado en representaciones determinadas. No se comprende que las ideas que se pretenden realizar son efectivamente parte del mundo que se quiere cambiar a partir de ellas. Son las ideas que resultan de las relaciones que establecen los individuos en el proceso de intercambio a través del cual se produce la mediación del metabolismo social. Y son como tales ideas necesarias para que en ese mundo se pueda producir la articulación de las esferas de la producción y la circulación, de modo que el trabajo privado se pueda constituir en parte del trabajo social global y se haga posible la reproducción de esta formación social. Las ideas de libertad e igualdad de la sociedad burguesa no son más que la otra cara de la explotación del trabajo asalariado.

\section{Relación entre las leyes de propiedad de la producción mercantil y las leyes de apropia- ción capitalista}

Para comprender cuáles son las verdaderas leyes de apropiación que operan en la sociedad capitalista es preciso partir de la relación de clase que está a la base del sistema. En primer lugar, hay que tener presente que sólo la separación de los productores directos de los medios de producción y la concentración de éstos en manos de los poseedores de dinero ha podido dar lugar a la relación constitutiva del sistema capitalista entre los poseedores «libres» de la mercancía fuerza de trabajo, que pueden y tienen que venderla en el mercado, y los poseedores de dinero y medios de producción, que compran esta mercancía a su valor y pueden consumir íntegramente su valor de uso.

Esta relación está presupuesta al proceso de producción capitalista, y Marx explicará al final de la exposición de las categorías fundamentales de este proceso cuáles fueron los acontecimientos históricos fundamentales a través de los cuales se constituyó, mientras que a lo largo de su exposición parte de esta relación como algo dado. Pero al considerar el proceso de producción en su fluencia continua, se constata ya que el funcionamiento mismo del sistema capitalista reproduce permanentemente esta relación que constituye su propio presupuesto.

«El proceso capitalista de producción, considerado en su conexión o como proceso de reproducción, produce, por tanto, no sólo mercancías, no sólo plusvalor, sino que produce y reproduce la relación de capital misma, por un lado el capitalista, por el otro el trabajador asalariado» ${ }^{38}$

38 Das Kapital, MEW 23, p. 604. En los Resultados del proceso de producción inmediato señala Marx respecto a su concepción de la reproducción de la relación de capital sobre la que se funda el modo de producción capita- 
Esta determinación de la relación de clase que está a la base del funcionamiento del modo de producción capitalista lleva a una comprensión del proceso histórico a partir del cual ha surgido esta formación social radicalmente distinta de la concepción de la economía política. Mientras ésta considera a los capitalistas como individuos laboriosos y ahorradores, que gracias a estas virtudes pudieron acumular y utilizar lo acumulado para producir más, Marx va a poner de manifiesto que esta «acumulación originaria» fue resultado de la violencia más brutal y sanguinaria organizada por la burguesía naciente en colaboración con los Estados para expropiar a las productores directos de sus medios de producción y luego obligarles a vender lo único que les quedaba, su fuerza de trabajo ${ }^{39}$.

Ahora bien, una vez consumada la expropiación del pueblo trabajador y establecida la relación de clase en la que se funda el modo de producción capitalista, basta la «violencia muda de las relaciones económicas $»^{40}$ para que esta relación se siga manteniendo. El Estado se limita entonces a garantizar la propiedad privada y las bases jurídicas de las relaciones contractuales en las que los individuos valen como personas libres e iguales. El trabajador establece un contrato en pie de igualdad con el capitalista, en virtud del cual recibe el valor de su mercancía fuerza de trabajo (y el capitalista, también conforme al derecho, puede hacer un uso pleno de la mercancía comprada por él), y el trabajador es libre de vender su mercancía a uno u otro capitalista (si bien la tiene que vender a uno de ellos) ${ }^{41}$. La igualdad formal de los individuos y la libre propiedad sobre sus mercancías bastan para que el sistema siga reproduciendo la relación de clase que constituye el fundamento del mismo.

Este análisis del proceso de producción del capital tiene implicaciones inmediatas sobre la comprensión de la verdadera ley de apropiación en la que se basa el sistema capitalista. Marx pone de manifiesto que la representación de la apropiación por el trabajo propio tiene a su base las condiciones de la moderna sociedad burguesa, y no refleja relaciones preburguesas, sino que simplemente proyecta sobre éstas la visión que surge de las determinaciones formales de la circulación simple como esfera abstracta de la sociedad moderna ${ }^{42}$. El hecho

lista: «Ésta es una concepción esencialmente distinta de la de los economistas burgueses, atrapados en las representaciones capitalistas, que ven ciertamente cómo se produce dentro de la relación de capital, pero no cómo se produce esta relación misma» (Resultate des unmittelbaren Produktionsprozesses, MEGA II.4.1, p. 129).

39 Frente a la concepción idílica que tiene la economía burguesa del proceso de «acumulación originaria», Marx hace patente cuáles fueron los verdaderos resortes de la misma: «La burguesía naciente necesita y utiliza el poder del Estado para «regular» el salario, es decir, para contenerlo forzadamente dentro de los límites favorables a la producción de plusvalor, para alargar la jornada laboral y mantener al trabajador mismo en el grado de dependencia normal. Es éste un momento esencial de la llamada acumulación originaria» (Das Kapital, MEW 23, pp. 765-766).

40 Ibid., p. 765.

41 En relación a ello señala Marx que «el cambio constante de patrón individual y la fictio juris del contrato permiten mantener la apariencia de que el trabajador asalariado es independiente» (ibid., p. 599).

42 Heinrich subraya que esta crítica de Marx no tiene ninguna pretensión «normativa», según la cual se estarían contraponiendo unas leyes de apropiación justas a unas injustas, sino que está dirigida exclusivamente a mostrar el origen de la comprensión que la sociedad burguesa tiene de sí misma: «Marx no designa como «transmutación de las leyes de apropiación» un desarrollo histórico con consecuencias normativas, sino la destrucción de la apariencia de «naturalidad» que confiere su legitimación a la «ley de apropiación originaria». Por consiguiente, no se trata para Marx de una argumentación normativa, sino de mostrar la génesis (estructural, no histórica) de las normas consideradas como evidentes en la sociedad burguesa ... se trata de demostrar que las representaciones normativas reciben su evidencia sólo desde la base de determinadas relaciones de producción» (Die Wissenschaft vom Wert, op. cit., p. 378). 
de que los productos sean mercancías y se presenten en el mercado para ser intercambiados no es algo natural, correspondiente a todas las sociedades históricas. Sólo en la sociedad burguesa se ha desarrollado plenamente la circulación simple, de modo que las ideas a ella correspondientes se pueden considerar como dominantes en todas las relaciones sociales. Esto significa que lo que aparece como la condición originaria y natural de todo intercambio en la sociedad burguesa tiene a su vez otros presupuestos, los cuales no resultan visibles desde la propia esfera de la circulación. Se pone así de relieve que la ley de apropiación a partir del trabajo propio no es más que la apariencia ideológicamente funcional de la circulación simple.

«De ahí que todos los economistas modernos declaren el trabajo propio como el título de propiedad original y la propiedad que es resultado del trabajo propio como el presupuesto fundamental de la sociedad burguesa. El presupuesto mismo se basa en el presupuesto del valor de cambio en cuanto relación económica que domina la totalidad de las relaciones de producción y de intercambio, y él mismo es, por tanto, un producto histórico de la sociedad burguesa, de la sociedad del valor de cambio desarrollado» ${ }^{43}$

En efecto, puesto que desde la perspectiva de la circulación, que es la que adopta la economía burguesa, tiene que darse el intercambio de equivalentes y, por tanto, nadie puede ser robado o explotado, la única fuente posible para la adquisición de la mercancía ajena tiene que ser el trabajo propio contenido en la propia mercancía. De este modo, el trabajo propio constituye el título de propiedad original para la teoría económica burguesa, que así sanciona teóricamente la comprensión espontánea de la conciencia burguesa, para la cual la apropiación del trabajo ajeno es resultado exclusivamente del trabajo propio ${ }^{44}$.

La diferencia entre la economía política clásica y la economía vulgar la ve Marx en que la primera es capaz de distinguir entre el intercambio simple y el intercambio entre capital y trabajo, considerando que en el segundo tipo de intercambio se presentan contradicciones con la ley de apropiación por el trabajo propio. Pero la economía política no es capaz de resolver estas contradicciones, y lo que hace es desplazar el problema, planteando la existencia de una época preburguesa en la que dominaba el intercambio simple y tenía validez la ley de apropiación por el trabajo propio, mientras que en la época burguesa se presenta una modificación de la misma, de modo que sólo vale de manera limitada:

«Puesto que la consideración de relaciones económicas más concretas que las que presenta la circulación simple parece dar como resultado leyes contradictorias, todos

43 Urtext, MEGA II.2, p. 48.

44 Esto se debe a que los economistas burgueses, del mismo modo que los agentes de la producción capitalista, sólo perciben la apariencia objetiva de las relaciones. También los grandes economistas clásicos, aunque han conseguido determinar elementos importantes de la conexión interna, vuelven a caer en una comprensión de las relaciones económicas que permanece en su forma de manifestación: «Incluso sus mejores portavoces permanecen atrapados, como no puede ser de otro modo desde el punto de vista burgués, en el mundo de la apariencia disuelto críticamente por ellos en mayor o menor medida, y caen, por tanto, en inconsecuencias, insuficiencias y contradicciones no resueltas» (Das Kapital III, MEW 25, p. 838). 
los economistas clásicos, incluido Ricardo, gustan de hacer valer como ley general esa visión que surge de la sociedad burguesa misma (aus der bürgerlichen Gesellschaft selbst entspringende Anschauung), pero desplazan su realidad estricta a la Edad de Oro, cuando todavía no existía ninguna propiedad. Por así decir, a la época anterior al pecado original económico, como dice, por ejemplo, Boisguillebert. De modo que se llegaría al insólito resultado de que habría que trasladar la verdad de la ley de apropiación de la sociedad burguesa a una época en que esta sociedad misma todavía no existía, y la ley básica de la propiedad a la época en la que no había propiedad. Esta ilusión es diáfana» ${ }^{45}$

La economía política no puede comprender que sólo una vez que se ha consumado el proceso de división en clases dentro de la sociedad es posible que se encuentren todos los miembros de la misma en la esfera de la circulación como personas libres e iguales sometidas a las mismas leyes del intercambio mercantil ${ }^{46}$. Por lo tanto, que dichas relaciones son el resultado de un proceso histórico previo en el que los productores directos han quedado expropiados de sus medios de producción, de modo que ya no les queda otra cosa que vender que su fuerza de trabajo, la cual puede ser comprada por los poseedores de dinero y medios de producción que, en la relación con la fuerza de trabajo, funcionan como capital. Las aporías a las que se ven confrontados los economistas burgueses en sus teorías les llevan en última instancia a proyectar las ideas que surgen de la circulación a una supuesta época originaria.

De una manera más clara aún dice Marx en las Teorías sobre el plusvalor sobre la ley de apropiación originaria que «esta ley fundamental es una pura ficción, surge de la apariencia de la circulación mercantil», a partir de la cual «parece como si los individuos intercambiaran sólo su propio trabajo» ${ }^{47}$. Respecto a esta apariencia afirma a continuación:

«En la producción capitalista desaparece esta apariencia que muestra su propia superficie (dieser Schein, den ihre eigene Oberfläche zeigt). Pero lo que no desaparece es la ilusión de que los hombres se enfrentan originariamente sólo como poseedores de mercancías y que, por tanto, cada uno sólo es propietario en tanto que es trabajador. Este «originariamente» es, como se ha dicho, una ilusión que surge de la apariencia de la producción capitalista, y que no ha existido nunca históricamente» 48

Cuando Marx habla aquí de «ficción» y de «ilusión» no se está refiriendo a que sean representaciones generadas conscientemente por el pensamiento burgués para justificar las relaciones sociales burguesas, sino que son una apariencia que surge necesariamente de dichas relaciones. Las leyes de la apropiación de la producción mercantil se transforman

45 Urtext, MEGA II.2, p. 49.

46 Marx insiste en que esto se debe al punto de vista burgués de la economía política, lo que constituye el límite insuperable de los economistas, incluido Ricardo: «Estas interpretaciones erróneas de Ricardo son consecuencia evidentemente de que no tenía una visión clara del proceso, ni podía tenerla, debido a condición de burgués» (Grundrisse, MEW 42, p. 456).

47 Theorien über den Mehrwert, MEW 26.3, p. 369.

48 Ibid. 
así en el curso de la exposición en leyes de la apropiación capitalista, porque aquellas leyes no son más que el reflejo de las relaciones de intercambio que tienen lugar en la superficie de la sociedad burguesa, quedando descodificadas como una mera proyección que surge de esas relaciones, las cuales se sustentan sobre las relaciones de producción capitalistas.

Así pues, las relaciones de intercambio que la conciencia burguesa considera como constitutivas de las relaciones sociales burguesas, y que son tomadas como el punto de partida por la economía política, son reducidas a momentos abstractos del proceso global en la exposición marxiana. Por lo tanto, las leyes que regulan esas relaciones no son históricamente originarias, sino surgidas en la historia conjuntamente con las leyes de apropiación capitalista. Con ello se hace patente que no son leyes naturales, sino resultado de una forma histórica de organización social de los hombres que tiene a su base relaciones de producción que son totalmente ajenas a esas leyes. A partir de aquí, Marx pone de manifiesto que las representaciones que se derivan de las relaciones de intercambio de la sociedad burguesa no corresponden a las relaciones sociales de ese sistema económico históricamente determinado que es el capitalismo, y que tampoco han existido en ninguna época anterior, sino que son la imagen refleja que esa sociedad tiene de sí misma. 